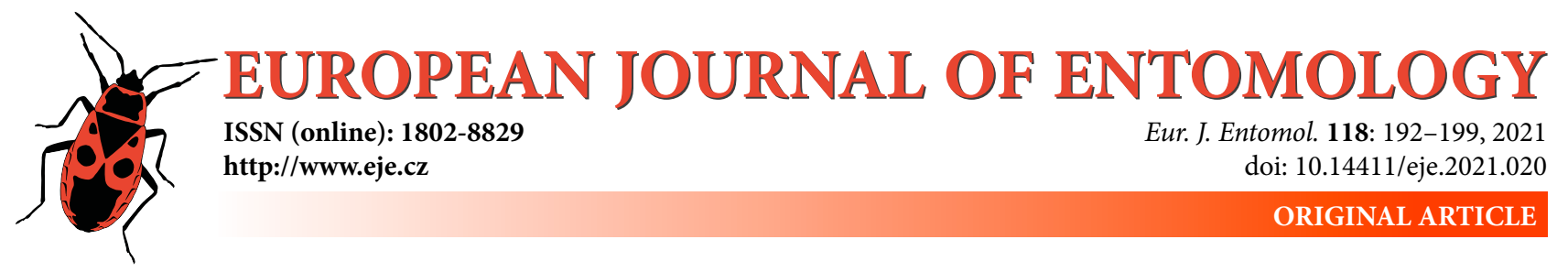

\title{
Blattodea Karyotype Database
}

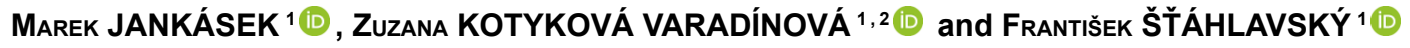 \\ ${ }^{1}$ Department of Zoology, Faculty of Science, Charles University, Viničná 7, 12844 Praha 2, Czech Republic; \\ e-mails: jankasem@natur.cuni.cz, zuzana.varadinova@natur.cuni.cz, frantisek.stahlavsky@natur.cuni.cz \\ ${ }^{2}$ Department of Zoology, National Museum, Václavské náměstí 68, 11579 Praha 1, Czech Republic
}

Key words. Blattodea, Isoptera, cockroach, termite, chromosome number, karyotype, meiosis, sex chromosome system, online database

\begin{abstract}
We present an open (publicly available) and updatable database of the karyotypes of Blattodea which is available at http://web.natur.cuni.cz/zoologie/arthropods/blattodeadatabase/index.html. This database currently contains data on chromosome numbers and sex chromosome systems for 355 (209 cockroaches and 146 termites) cytogenetically and/or geographically distinct populations of 229 species (138 cockroaches and 91 termites). When available, data on chromosome morphology and fundamental number are also included. As this summary of the data on Blattodea cytogenetics follows current taxonomy and phylogeny it enabled us to discuss hypotheses on karyotype evolution. We also point out some cytogenetically interesting phenomena such as extensive karyotype differentiation at low taxonomic levels in some lineages and the change from the X0 sex chromosome system, which is present in cockroaches, to systems with multiple neo-sex chromosomes, present in termites. We encourage the use of modern cytogenetic methods in research on Blattodea cytogenetics to uncover more detailed mechanisms of karyotype evolution in this insect order. We also provide a brief summary of the history of cytogenetic research in Blattodea.
\end{abstract}

\section{INTRODUCTION}

Blattodea is the second largest polyneopteran (Neoptera, Insecta) order comprising approximately 7600 species, of which 4600 are cockroaches and 3000 are termites (Krishna et al., 2013; Beccaloni, 2014). They are morphologically very variable and exhibit a great diversity of lifehistories, including the evolution of eusociality in termites (Bell et al., 2007; Bignell et al., 2011). In addition, synanthropic cockroaches and termites, as ecosystem engineers, have an incalculable global ecological and economic effect (Bell et al., 2007; Bignell et al., 2011). Based on the current state of knowledge, Blattodea also exhibit remarkable cytogenetic diversity in chromosome numbers and morphology, sometimes even between closely related lineages. Moreover, there is great variability in the sex chromosome systems (SCSs) in termite lineages, ranging from $\mathrm{X} 0$ and $\mathrm{XY}$ systems to X(1-9)Y(1-8) in Kalotermes approximatus Snyder, 1920 or X(1-9)Y(1-7) arranged in two permanent multivalents in males of Neotermes fulvescens (Silvestri, 1901) (Syren \& Luykx, 1981; Luykx, 1990; Martins \& Mesa, 1995).

The early cytogenetic research on cockroaches (non-termite Blattodea) includes works of Stevens (1905), Morse (1909), Wassilieff (1907) and Suomalainen (1946). Their studies describing the process of gametogenesis revealed the presence of the XX/X0 SCS. Subsequent research fo- cused on chromosomal races of the obligatory parthenogenetic species Pycnoscelus surinamensis (Linnaeus, 1758) and its bisexual ancestor Pycnoscelus indicus (Fabricius, 1775) (Matthey, 1945, 1948; Roth, 1967; Roth \& Cohen, 1968) and the description of chromosome numbers and spermatogenesis in other species of cockroaches (Piza, 1958). Significant attention was also given to chromosomal mutations resulting in formation of autosomal multivalents in Periplaneta americana (Linnaeus, 1758) (Lewis \& John, 1957; John \& Lewis, 1958; John \& Qijraishi, 1964), Blaberus discoidalis Serville, 1838 (John \& Lewis, 1959) and Blattella germanica (Linnaeus, 1767) (Cochran \& Ross, 1961, 1967, 1969, 1977a, b; Ross \& Cochran, 1971, 1975, 1976, 1977, 1979, 1981). Moreover, Cohen \& Roth (1970) presented chromosome counts for 84 species with approximate descriptions of chromosome morphology, an enormous contribution to cockroach cytogenetics. The last synthesis of cockroach cytogenetics, done by White (1976), summarized most of the above-mentioned data.

The long-lasting debate on phylogenetic relationships between cockroaches and termites has been largely settled by studies providing strong support for termites as a highly derived group of "eusocial cockroaches" with sister affiliation to wood-feeding cockroaches of the family Cryptocercidae (Lo et al., 2000; Inward et al., 2007). The new perspective led to a wave of cytogenetic research focused on 
this family. An extensive karyotyping of this lineage was initiated using species of the North American Cryptocercus (Luykx, 1983; Nalepa et al., 2002, 2017), in which chromosome fusions are thought to have had an important role in karyotype evolution (Nalepa et al., 2002). Chromosome fusions and fissions, also seem to be the main mechanisms of karyotype evolution in Asian species of Cryptocercus (Wang et al., 2019). Furthermore, recently described species of Cryptocercus from China are supported by their different diploid chromosome numbers (Che et al., 2016; Bai et al., 2018; Wang et al., 2019).

In his monograph, White (1976) also reviewed the state of knowledge of termite cytogenetics at that time. He drew mainly from the pioneering works on termite cytogenetics by Stevens (1905), Benkert (1930a, b, 1933), Light (1938, 1942) and Banerjee (1957, 1961). They describe spermatogenesis in several species and uncovered the diploid character of the male chromosome complements. This is in sharp contrast to the haplo-diploid system known at that time in other eusocial insects (Hamilton, 1964). Although White (1976) states that nothing is known about sex chromosomes in termites, Vincke (1974) proposes an $\mathrm{X} 0 / \mathrm{XX}$ SCS for "lower termites" in his earlier work. In addition to that, Vincke (1974) reports a ring tetravalent in male karyotypes of several species of "higher termites", hypothesising that the chromosomes forming this structure are probably sex chromosomes. In contrast to the situation with cockroaches, intensive work on termite cytogenetics was carried out after White's (1976) review. Importantly, it was confirmed that male specific multivalents consisted of neo-sex chromosomes resulting from multiple reciprocal interchanges and, in some cases, chromosome fusions (Syren \& Luykx, 1977, 1981; Fontana, 1980, 1982; Luykx, 1990; Martins \& Mesa, 1995). The role of these multivalents in termite eusociality or its dynamics and fixation in termite populations were hotly debated topics (Lacy, 1980, 1984; Leinaas, 1983; Crozier \& Luykx, 1985; Rowell, 1986; Bedo, 1987; Charlesworth et al., 1987; Luykx, 1990; Fontana, 1991; Charlesworth \& Wall, 1999; Husseneder et al., 1999).

The overall increase in the amount of data on chromosome numbers, chromosomal sex determination systems and radical changes in the phylogenetic relationships within Blattodea since White's review call for the establishment of a new synthesis of Blattodea cytogenetics. A continually updated online database available to all researchers would be especially beneficial. One such database, including data on chromosome numbers and SCSs of Blattodea was recently presented in a study focused on karyotype evolution in Polyneoptera (Sylvester et al., 2020) and this dataset is also included in Tree of Sex Database (The Tree of Sex Consortium, 2014). This study evaluated ancestral states of chromosome numbers and SCSs for orders of Polyneoptera together with rates of chromosome fusions, fissions and polyploidy. Unfortunately, a number of the records of Blattodea karyotypes are missing in the dataset of that study. Notably, only two citations, White (1976) and Bergamaschi et al. (2007), are provided for cockroaches (last accessed $6^{\text {th }}$ May 2021). Furthermore, instead of citing the original publications of karyotype descriptions, White's review is most often provided as a single source for most records. The database of Sylvester et al. (2020) also does not differentiate between hypothesized data and those which were directly observed (e.g. chromosome numbers were observed only in one sex and the number in the other sex is only the "expected" number). For example, this could result in an over simplified view of Blattodea SCSs since the X0 system is only "expected" in the many species, where a male karyotype was not observed. Also, this database omits important taxonomical changes and details concerning the current knowledge on this group. For example, genus Cryptocercus is either ranked as Polyphagidae or Blattidae, but belongs to the family Cryptocercidae (Beccaloni, 2014). Considering the limitations of Polyneoptera Karyotype Database, we decided to create a new publicly available and updatable database of Blattodea karyotypes, which (1) includes data from the original papers and (2) follows the currently accepted taxonomy for the group. This enables us to explore evolutionary trends between phylogenetic lineages and suggest interesting directions for future research.

\section{MATERIALS AND METHODS}

This Blattodea Karyotype Database includes information on chromosome number, SCSs, chromosome morphology and number of chromosome arms ("nombre fundamental" - NF) in cockroaches and termites. The data were gathered exclusively from original descriptions of karyotypes, despite some of them having been already summarized in White's (1976) review. Additional research articles including data on Blattodea cytogenetics were searched for on Google Scholar and Web of Science using "cockroach chromosome", "cockroach karyotype", "termite chromosome" and "termite karyotype" as keywords. Species names and their assignment to higher taxa were updated according to the current state of knowledge. We followed the taxonomy of the Cockroach Species File (Beccaloni, 2014) and the revision of Evangelista et al. (2020) for cockroaches and the Treatise on the Isoptera of the World (Krishna et al., 2013) for termites. In very rare cases karyotypes were recorded before the species was identified. Thus, species identification had to be searched for in later descriptions or taxonomic revisions. For example, Cohen \& Roth (1970) report chromosome numbers of "undetermined genus (41B)" of the cockroach subfamily Zetoborinae, which was described as a new genus and species Schultesia lampyridiformis three years later (Roth, 1973). If the name of a karyotyped species differed from the currently valid name, or if it was identified later, we provide the name used in the publication of the original karyotype description in the section "Cited as". Comments on the possible erroneous identification of karyotyped material or its re-description are included in the "Notes" section in the database. Since chromosome morphology was not studied in detail in many of the original publications, we determined the morphology formulas for those species where karyotype pictures were of satisfactory quality. The morphometric measurements were done in ImageJ software using Levan plugin (Sakamoto \& Zacaro, 2009) and following the nomenclature established by Levan et al. (1964). However, some authors studying the cytogenetics of Blattodea did not follow the standardized nomenclature for chromosomal morphology. They frequently pooled metacentric (M) and submetacentric (SM) chromosomes into a single category of two- 


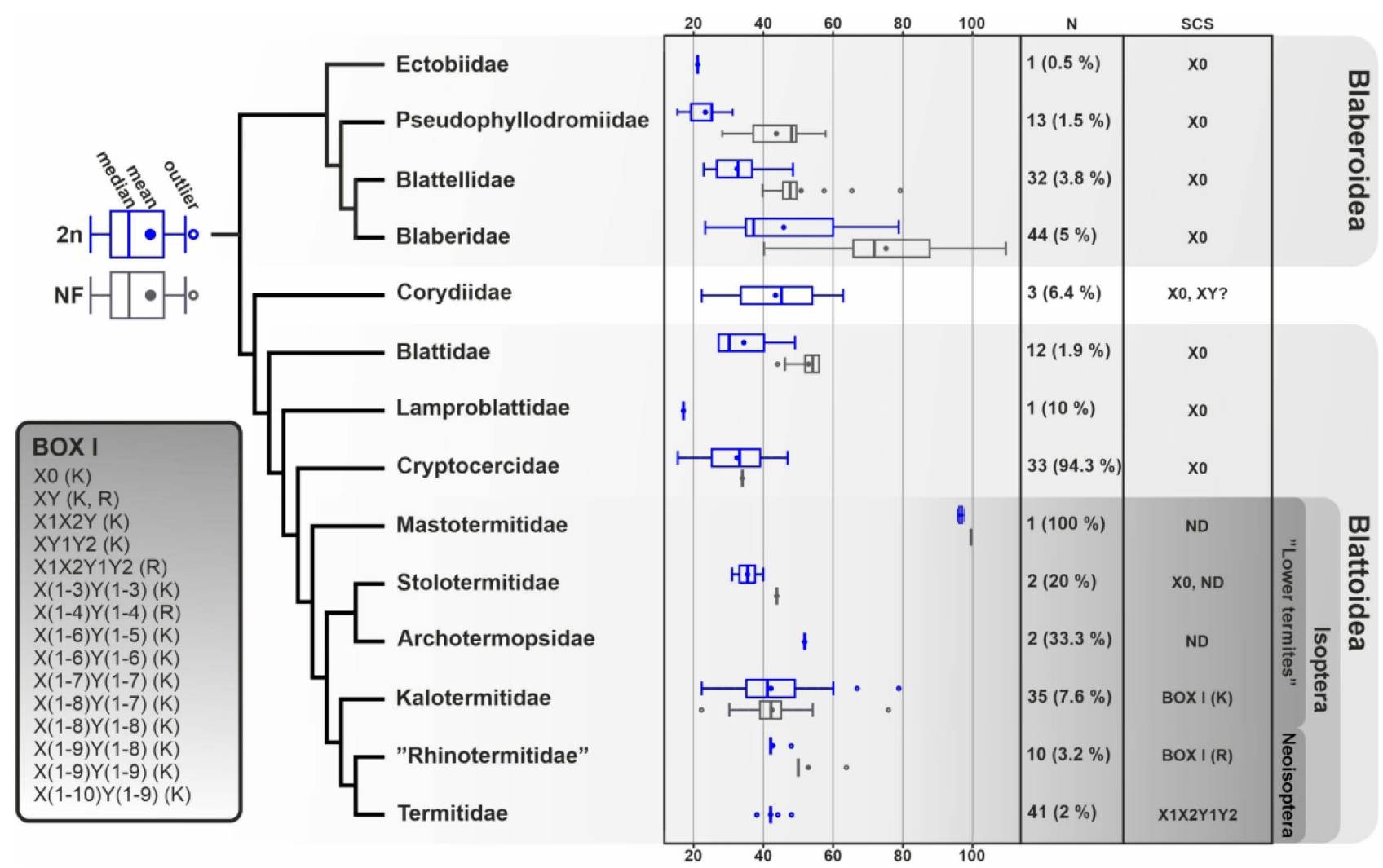

Fig. 1. Cladogram illustrating evolutionary relationships between the cytogenetically studied families of Blattodea following Bourguignon et al. (2015) and Evangelista et al. (2019, 2020). $2 n$ - male diploid chromosome numbers of all the populations studied are in the form of boxplots with highlighted mean and median number; NF - female number of major chromosome arms in form of boxplots with highlighted mean and median number; $\mathrm{N}$ - total number and percentage of species with known male diploid chromosome number; ND - nondifferentiated sex chromosomes; SCS - sex chromosome system; ? - data need confirmation by wider sampling.

armed chromosomes, and subtelocentric (ST) and telocentric (T) chromosomes into a single category of one-armed chromosomes (using the term "acrocentric"). We keep such records in our database as they were originally published. In order to compare the $\mathrm{NF}$ and chromosome morphology measurements obtained by us with the data from publications using alternate nomenclature systems, we also treat the subtelocentric chromosomes as one-armed, even though it might be inconsistent with cytogenetic research in other animal taxa (e.g. Glugoski et al., 2020). The NF is presented in diploid chromosome number for both females [NF (f)] and males $[\mathrm{NF}(\mathrm{m})]$ and was counted as number of chromosomes in the karyotype plus the number of two-armed chromosomes. Meanings of the symbols used to provide a better orientation in the database are summarized in Table 1 . The data on chromosome numbers, NF and SCSs in particular families of Blattodea were mapped on the phylogeny following Bourguignon et al. (2015) and Evangelista et al. (2019, 2020) (Fig. 1).

\section{RESULTS AND DISCUSSION}

Our online Blattodea Karyotype Database is available at http:/web.natur.cuni.cz/zoologie/arthropods/blattodeadatabase/index.html. It currently comprises records for 355 (209 cockroaches and 146 termites) cytogenetically and/or geographically distinct populations of 229 species of Blattodea (138 cockroaches and 91 termites).

\section{Cockroaches}

The greatest range of chromosome numbers in cockroaches is recorded in the family Blaberidae $(2 \mathrm{n} \hat{0}=23-79$, Fig. 1), with subfamilies Blaberinae $(2 \mathrm{n} \widehat{\gamma}=31-73)$, Oxyhaloinae $(2 \mathrm{n}+=24-76)$ and Zetoborinae $(2 \mathrm{n} \odot=30-66)$ the most variable. The widest range in chromosome diploid numbers in the subfamily Blaberinae is found within the species-rich genus Blaberus $\left(2 \mathrm{n}{ }^{\lambda}: 37,39,73\right)$. In the African subfamily Oxyhaloinae, the major difference in chro-

Table 1. List of symbols used in the Blattodea karyotype database.

\begin{tabular}{|c|c|}
\hline Symbol & Meaning \\
\hline$?$ & Data assumed by the authors of original publication \\
\hline * & Our assumption based on the most probable state of characters supported by information from other publications \\
\hline “ & Our morphology measurements and NF calculations \\
\hline \# & Only bivalents present at metaphase I \\
\hline$\partial \mathrm{C}$ & Chain of sex chromosomes present at male metaphase I (followed by number of participating chromosomes) \\
\hline$\partial \mathrm{R}$ & Ring of sex chromosomes present at male metaphase I (followed by number of participating chromosomes) \\
\hline
\end{tabular}


mosome numbers is between continental $(2 \mathrm{n} \cap=24,38)$ and Madagascan $(2 \mathrm{n}+=64,76)$ representatives. Species in the subfamilies Panesthiinae and Geoscapheinae were recently shown to form a monophyletic group, since species of Geoscapheinae are nested within Panesthiinae (Lo et al., 2016; Djernæs et al., 2020). This Panesthiinae sensu lato (Djernæs et al., 2020) clade exhibits another example of a great difference in chromosome numbers and also the highest known chromosome number recorded for cockroaches $(2 \mathrm{n} \widehat{\jmath}=37,79)$. Other families, which manifest relatively wide ranges in chromosome numbers include Corydiidae $(2 \mathrm{n} \widehat{\circlearrowleft}=22-63)$, Blattidae $(2 \mathrm{n} \hat{\bigcirc}=27-47)$ and Blattellidae $(2 \mathrm{n} \widehat{O}=23-49)$ (Fig. 1). In contrast, families Pseudophyllodromiidae $(2 \mathrm{n} \bigcirc=16-32)$, Ectobiidae $(2 \mathrm{n} \hat{\bigcirc}=21)$ and Lamproblattidae $(2 \mathrm{n} \hat{\sigma}=17)$ seem to have relatively low chromosome numbers, although only a very small proportion of their diversity was karyotyped (Fig. 1). No species of the families Anaplectidae, Nocticolidae, Nyctiboridae and Tryonicidae have been karyotyped. Lastly, the monotypic family Cryptocercidae, with 33 species karyotyped, is now cytogenetically the best-characterized cockroach group. A wide range of chromosome numbers is recorded for the whole Cryptocercus genus: it ranges from $2 \mathrm{n} \widehat{\delta}=$ 37 to $2 \mathrm{n} \hat{O}=47$ in North American species and from $2 \mathrm{n} \circlearrowleft$ $=15$ to $2 \mathrm{n} \delta=45$ in Asian species (Luykx, 1983; Nalepa et al., 2002, 2017; Lo et al., 2006; Che et al., 2016; Bai et al., 2018; Wang et al., 2019). It is suggested that serial chromosomal fusions resulted in the karyotypes of North American Cryptocercus populations (Burnside et al., 1999; Lo et al., 2006, but see Clark et al., 2001), but the exact chromosomal rearrangements producing the karyotype variability in Asian Cryptocercus species remain unknown. Our findings are consistent with the results of Sylvester et al. (2020), in which the Blattodea is the most variable Polyneoptera order in terms of chromosome numbers and high rates of chromosomal fissions and fusions.

Despite the fact that numerous cockroach karyotypes are described, detailed information on chromosome morphology and/or NF is mostly missing in the literature. We were only able to add the precise measurements of chromosomes and NF for a relatively small proportion of species due to the poor quality of metaphase pictures. We were also unable to measure the data for both sexes in most of the species, since the photographic material usually included only the karyotype of one sex (mostly females). As a result, the information on chromosome morphology and NF is scarce and unequally distributed among cockroach families. Nonetheless, Blaberidae subfamilies Oxyhaloinae ( $\mathrm{NF}=$ $46,72,94)$, Pycnoscelinae (NF = 66-106) and Zetoborinae $(\mathrm{NF}=68,110)$ are obviously very variable in their chromosome morphology and NF. Roth \& Cohen (1968) studied the cytogenetically polymorphic Pycnoscelus indicus and $P$. surinamensis complex. They hypothesized that the high variation in the karyotype of the parthenogenetic species $P$. surinamensis, which apparently arose from the bisexual $P$. indicus, is a consequence of polyploidization and/or the possible polyphyletic character of the species. Indeed, evidence indicates that polyploid species are predominantly asexual in insects (Otto \& Whitton, 2000). Although NF of Oxyhaloinae and Zetoborinae strongly differ between the species studied, polyploidization does not seem to be a plausible explanation as numbers of chromosomes in particular morphological categories are disproportionally distributed between species with high and low chromosome numbers. Centric fissions/fusions or Robertsonian translocations (RT) seem to be much more plausible explanations, since species with high chromosome numbers have relatively more telocentric and subtelocentric chromosomes. To better understand mechanisms involved in the karyotype evolution of closely related species, data on genome size should be recorded in future studies. Also, definite conclusions cannot be drawn if the phylogenetic relationships of the focal group are unknown.

The only known SCS in cockroaches is X0. However, it is important to note that an X0 system is only assumed for many cockroach species since the chromosome numbers for both sexes are not always available $(2 \mathrm{n} \delta$ is not confirmed in $45 \%$ of the cytogenetically studied cockroach species). The only known potential exception to this SCS in cockroaches is the genus Latindia (Corydiidae: Latindiinae) where the male diploid chromosome number is 22 and an XY system is expected. However, the authors themselves note that these counts must be confirmed by further studies (Cohen \& Roth, 1970). Because the X chromosome is metacentric in most cockroaches, White (1976) hypothesized that it is unavailable for centric fusions, and thus the origin of neo-XY SCS by direct fusion between original $\mathrm{X}$ and an autosome is not possible. Although we do not know any case of the occurrence of neo-XY SCS in cockroaches, its existence cannot be excluded since a neoSCS could be derived by reciprocal translocation between an $\mathrm{X}$ chromosome and an autosome, which is the process by which an X1X2Y SCS arose from X0 SCS in Mantodea (White, 1976).

\section{Termites}

The highest numbers of chromosomes reported in termites, and also the whole Blattodea, are present in Mastotermitidae $(2 \mathrm{n} \widehat{\jmath}=96,98)$ (Bedo, 1987; Luykx, 1990; Luykx et al., 1990; Bergamaschi et al., 2007), a family with a single extant species, Mastotermes darwiniensis Froggatt, 1897, which is a sister lineage to all other termites (Bourguignon et al., 2015; Bucek et al., 2019). Despite its position in termite phylogeny, the very high number of chromosomes in the Mastotermes karyotype is so unique that it cannot be automatically assumed to be an ancestral state (Luykx, 1990). Documented karyotypes in the clade including families Archotermopsidae $(2 \mathrm{n} \delta$ and $2 \mathrm{n}+=52$ ) (6 species, 2 karyotyped) and Stolotermitidae $(2 \mathrm{n}+=40,32)$ (10 species, 2 karyotyped) also probably do not represent an ancestral state. However, the average number of chromosomes $(2 \mathrm{n} \widehat{O}=41$ and $2 \mathrm{n} \uparrow=41,3)$ in the whole clade is very close to 42 , the most common number recorded in Neoisoptera (Rhinotermitidae, Serritermitidae, Stylotermitidae and Termitidae) and the average number in Kalotermitidae. The Kalotermitidae is exceptional in termites in having the widest range of chromosome num- 
bers $(2 \mathrm{n} \hat{0}=22-63)$, which may be partially explained by chromosome fissions and fusions (Luykx, 1990). Given the current hypothesized phylogeny of termites, the last common ancestral chromosome number was probably $2 \mathrm{n}$ $=42$, at least in recent termite lineages. This assumption is consistent with results of recent analyses, where haploid chromosome numbers 20,21 and 22 are reported to be the most probable ancestral states for termites (Sylvester et al., 2020). Even though many cytogenetic records for termites were not included in the study of Sylvester et al. (2020), the relatively low rates of chromosome fissions and fusions in termites evaluated in this study is plausible since species rich Neoisoptera is conservative in terms of numbers of chromosomes and most of the variation from $2 n=42$ is present in old families of "lower termites". No representatives of Hodotermitidae, Serritermitidae and Stylotermitidae have been karyotyped until now.

Unlike cockroaches, chromosome morphology and NF are regularly described for karyotyped termites. However, for the families Archotermopsidae and Termitidae there is no such information despite the publication of many chromosome counts. Interestingly, the karyotypes of termites are mainly, or in some species of Kalotermitidae even exclusively, composed of one-armed chromosomes (ST/T). Evidence suggests that the evolution of SCSs in some species of Kalotermitidae is driven by centric fusions or Robertsonian translocations between original sex chromosomes and autosomes and may even be the cause of intraspecific variation (Luykx, 1990; Luykx et al., 1990). For example, two populations of the kalotermitid species Cryptotermes queenslandis (Hill, 1933) differ in their chromosome counts, with one having $2 \mathrm{n} \hat{\sigma}=42$ and the other $2 \mathrm{n} \hat{\jmath}$ $=41$. A single centric fusion of an original one-armed $\mathrm{Y}$ chromosome with an autosome resulting in the formation of a male specific trivalent of sex chromosomes is apparently responsible for this change in chromosome number (Luykx, 1990). On the other hand, the variability in NF records in our database indicate that the majority of differences in chromosome number at the interspecific level is not caused solely by centric fusions/fissions but also by other mechanisms of karyotype evolution. To better understand these processes, detailed phylogenetic analyses of species with described karyotypes and application of molecular-cytogenetic methods are desirable in future research.

It is also noteworthy that descriptions of chromosome morphology (and consequently the NF) of one or several closely related species may significantly differ between studies. For instance, Fontana (1982) report $20 \mathrm{M} / \mathrm{SM}$ and $47 \mathrm{ST} / \mathrm{T}$ chromosomes in males $(20 \mathrm{M} / \mathrm{SM}$ and $48 \mathrm{ST} / \mathrm{T}$ in females) of Kalotermes flavicollis (Fabricius, 1793), whereas Bergamaschi et al. (2007) report $8 \mathrm{M} / \mathrm{SM}$ and 59 $\mathrm{ST} / \mathrm{T}$ chromosomes in males $(8 \mathrm{M} / \mathrm{SM}$ and $60 \mathrm{ST} / \mathrm{T}$ in $\mathrm{fe}-$ males) for the same species. Similarly, Fontana (1980) and Fontana \& Goldoni (1985) report $22 \mathrm{M} / \mathrm{SM}$ and $20 \mathrm{ST} / \mathrm{T}$ chromosomes for both sexes of Reticulitermes lucifugus (Rossi, 1792), whereas Bergamaschi et al. (2007) report 8 $\mathrm{M}$ and $34 \mathrm{ST} / \mathrm{T}$ chromosomes in males of $R$. urbis Bagneres
\& Clément, 2003 and $R$. grassei Clément, 1978. Because the chromosome number is the same and only chromosome morphology differs, we think that this inconsistency is a result of different categorizations of chromosome morphology in these studies, and/or poor quality of karyotype pictures, rather than a real biological phenomenon. However, we cannot exclude the possibility of karyotype variability in these cases.

In contrast to cockroaches, the XY SCS is ancestral for recent termites (Sylvester et al., 2020) and was further modified by centric fusions or reciprocal translocations into various SCSs in many species (e.g. Vincke \& Tilquin, 1978; Fontana, 1980; Luykx, 1990; Martins \& Mesa, 1995). However, the change from the X0 system, present in the sister group Cryptocercidae and other cockroaches, to the XY system in termites remains to be studied. Only homomorphic bivalents are present at meiosis in both sexes in the basal M. darwiniensis (Bedo, 1987; Bergamaschi et al., 2007); thus even though the sex chromosomes are not morphologically differentiated in this species, we can exclude the presence of an X0 system or any derived translocation complexes (Bedo, 1987; Bergamaschi et al., 2007). More information on the origin of the termite Y chromosome might be obtained from the other "lower termite" families Archotermopsidae, Hodotermitidae and Stolotermitidae, which together form a monophyletic group (Bourguignon et al., 2015; Bucek et al., 2019; Legendre et al., 2015). The only species of this group with identified sex chromosomes is Stolotermes victoriensis Hill, 1921 (Stolotermitidae), which has an X0 SCS, while the other karyotyped species from the family Stolotermitidae, Porotermes adamsoni (Froggatt, 1897), has only bivalents at the first meiotic division and thus presumably an XY system (Luykx, 1990). In Archotermopsidae, males of Zootermopsis angusticollis (Hagen, 1858) (females not karyotyped) and females of $Z$. nevadensis (Hagen, 1874) (males not karyotyped) both have 52 chromosomes (Light, 1938; Stevens, 1905), which also indicates an XY system. Thus, the state in $S$. victoriensis seems to be derived. The last family of "lower termites", Kalotermitidae, is undoubtedly the most variable lineage in the Blattodea with respect to SCSs. Striking intraspecific variability is reported in Incisitermes schwarzi (Banks in Banks \& Snyder, 1920) (Syren \& Luykx, 1977; Luykx, 1987; Luykx \& Syren, 1979), Kalotermes approximatus (Syren \& Luykx, 1981) and K. flavicollis (Truckenbrodt, 1964; Fontana \& Amorelli, 1975; Fontana, 1982). This variability is caused by the sex chromosome multivalents forming circles or chains involving up to more than a half of the karyotype. Neoisoptera is, in addition to having a constant diploid number of 42 chromosomes, also very conservative in having a male specific tetravalent of sex chromosomes resulting from one reciprocal translocation between the original Y chromosome and an autosome (Vincke, 1974; Vincke \& Tilquin, 1978; Bergamaschi et al., 2007). The only exceptions are present in "Rhinotermitidae" where some species have only bivalents at meiosis (indicating an XY system with non-differentiated sex chromosomes) and several species 
exhibit intraspecific polymorphisms in SCSs, from having only bivalents at meiosis to having large male-specific sex chromosome multivalents (Fontana, 1980; Fontana \& Goldoni, 1985; Bergamaschi et al., 2007).

Our knowledge of the structure and function of the chromosomes of Blattodea is still very limited, but future studies in this area may indicate the emergence of interesting phenomena during karyotype evolution. Specifically, wide differences in chromosome numbers at small taxonomic scales, such as subfamily or genus levels, are reported in certain subfamilies of Blaberidae (Oxyhaloinae, Zetoborinae, Blaberinae, Panesthiinae sensu lato) or in representatives of Kalotermitidae (Cryptotermes, Kalotermes, $\mathrm{Ne}$ otermes). The chromosome fissions and fusions are known to have an important role in producing such variability (Sylvester et al., 2020), but without investigating the context of the small scale phylogeny or biogeography of these particular taxa, no detailed models of karyotype evolution describing these broad differences could be created. Many interesting features might also be revealed by studies on Blattodea SCSs, as they have not been mostly identified in cytogenetically studied cockroaches and are very dynamic in termites. Lastly, molecular-cytogenetic and genomic methods applied to studies on Blattodea might solve some of the most interesting problems, for example the origin of $\mathrm{Y}$ chromosome in termites and the homology of the $\mathrm{Y}$ and $\mathrm{X}$ chromosomes across Blattodea, or the mechanisms of rapid karyotype diversification in some specific lineages, such as Blaberidae, Cryptocercidae and Kalotermitidae.

ACKNOWLEDGEMENTS. We are grateful to W. Bourland and two anonymous reviewers for valuable comments and suggestions that improved this manuscript. This study was supported by the Grant Agency of Charles University (GA UK 722119) and SVV 260571/2021.

\section{REFERENCES}

Bai Q., Wang L., WAng Z., Lo N. \& Che Y. 2018: Exploring the diversity of Asian Cryptocercus (Blattodea: Cryptocercidae): species delimitation based on chromosome numbers, morphology and molecular analysis. - Invertebr. Syst. 32: 69-91.

BANERJEe B. 1957: Haploid chromosome numbers in the testis of the termite king Odontotermes redemanni. - Curr. Sci. 26: 288-289.

BANERJEE B. 1961: Chromosome morphology during the spermatogenesis of Odontotermes redemanni (Wasmann). — Caryologia 14: $155-158$.

Beccaloni G.W. 2014: Cockroach Species File Online. Version 5.0/5.0. URL: http://Cockroach.SpeciesFile.org.

BEDo D.G. 1987: Undifferentiated sex chromosomes in Mastotermes darwiniensis Froggatt (Isoptera; Mastotermitidae) and the evolution of eusociality in termites. - Genome 29: 76-79.

Bell W.J., Roth L.M. \& NALePA C.A. 2007: Cockroaches: Ecology, Behavior, and Natural History. Johns Hopkins University Press, Baltimore, 230 pp.

BenKert J.M. 1930a: Chromosomal study of Reticulitermes flavipes. - Proc. Pennsyl. Acad. Sci. 4: 1-3.

BenKert J.M. 1930b: Chromosome number of the male of the first form reproductive caste of Reticulitermes flavipes Kollar. - Proc. Pennsyl. Acad. Sci. 4: 97-99.
Benkert J.M. 1933: Comparison of the chromosome of soldier and king of Reticulitermes flavipes Kollar. - Proc. Pennsyl. Acad. Sci. 7: 121-122.

Bergamaschi S., Dawes-Gromadzki T.Z., Scali V., Marini M. \& Mantovani B. 2007: Karyology, mitochondrial DNA and the phylogeny of Australian termites. - Chromosome Res. 15: 735-753.

Bignell D.E., Roisin Y. \& Lo N. 2011: Biology of Termites: A Modern Synthesis. Springer, Dordrecht, 576 pp.

Bourguignon T., Lo N., Cameron S.L., Šobotník J., Hayashi Y., Shigenobu S., Watanabe D., Roisin Y., Miura T. \& Evans T.A. 2015: The evolutionary history of termites as inferred from 66 mitochondrial genomes. - Mol. Biol. Evol. 32: 406-421.

Bucek A., Šobotník J., He S., Shi M., McMahon D.P., Holmes E.C., Roisin Y., Lo N. \& Bourguignon T. 2019: Evolution of termite symbiosis informed by transcriptome-based phylogenies. - Curr. Biol. 29: 3728-3734.

Burnside C.A., Smith P.T. \& Kambhampati S. 1999: Three new species of the wood roach, Cryptocercus (Blattodea: Cryptocercidae), from the Eastern United States. - J. Kans. Entomol. Soc. 72: 361-378.

Charlesworth B. \& Wall J.D. 1999: Inbreeding, heterozygote advantage and the evolution of neo-X and neo-Y sex chromosomes. - Proc. R. Soc. Lond. (B) 266: 51-56.

Charlesworth B., Coyne J.A. \& Barton N.H. 1987: The relative rates of evolution of sex chromosomes and autosomes. - Am. Nat. 130: 113-146.

Che Y., Wang D., Shi Y., Du X., Zhao Y., Lo N. \& Wang Z. 2016: A global molecular phylogeny and timescale of evolution for Cryptocercus woodroaches. - Mol. Phylogenet. Evol. 98: 201-209.

Clark J.W., Hossain S., Burnside C.A. \& Kambhampati S. 2001: Coevolution between a cockroach and its bacterial endosymbiont: a biogeographical perspective. - Proc. R. Soc. Lond. (B) 268: 393-398.

Cochran D.G. \& Ross M.H. 1961: Balloon-wing, a new mutation in Blattella germanica (L.). - Virginia J. Sci. 12: 10-17.

Cochran D.G. \& Ross M.H. 1967: Preliminary studies of the chromosomes of twelve cockroach species (Blattaria: Blattidae, Blattellidae, Blaberidae). - Ann. Entomol. Soc. Am. 60: 1265-1272.

Cochran D.G. \& Ross M.H. 1969: Chromosome identification in the German cockroach. - J. Hered. 60: 87-92.

Cochran D.G. \& Ross M.H. 1977a: Cytology and genetics of a stable ring-of-six translocation in the German cockroach. $-J$. Hered. 68: 172-178.

Cochran D.G. \& Ross M.H. 1977b: The cytogenetics of T(11; $12)$, a reciprocal translocation in the German cockroach. $-J$. Hered. 68: 379-382.

Cohen S. \& Roth L.M. 1970: Chromosome numbers of the Blattaria. - Ann. Entomol. Soc. Am. 63: 1520-1547.

CROzIER R.H. \& LuYKX P. 1985: The evolution of termite eusociality is unlikely to have been based on a male-haploid analogy. - Am. Nat. 126: 867-869.

Djernes M., Kotyková Varadínová Z., Kotyk M., Eulitz U. \& KLAss K.-D. 2020: Phylogeny and life history evolution of Blaberoidea (Blattodea). - Arthropod Syst. Phylo. 78: 29-67.

Evangelista D.A., Wipfler B., Béthoux O., Donath A., Fujita M., Kohli M.K., Legendre F., Liu S., Machida R., Misof B. et AL. 2019: An integrative phylogenomic approach illuminates the evolutionary history of cockroaches and termites (Blattodea). - Proc. R. Soc. (B) 286(1895): 20182076, 9 pp.

Evangelista D., Simon S., Wilson M.M., Kawahara A.Y., Kohli M.K., Ware J.L., Wipfler B., Béthoux O., Grandcolas P. \& Legendre F. 2020: Assessing support for Blaberoidea phy- 
logeny suggests optimal locus quality. - Syst. Entomol. 46 $157-171$.

FonTANA F. 1980: Interchange complexes in Italian populations of Reticulitermes lucifugus Rossi (Isoptera: Rhinotermitidae). Chromosoma 81: 169-175.

FonTANA F. 1982: Cytological analysis of the chromosome complement of Kalotermes flavicollis Fabr. (Isoptera: Kalotermitidae). The sex determining mechanism. - Cytologia 47: $147-152$.

FonTANA F. 1991: Multiple reciprocal chromosomal translocations and their role in the evolution of sociality in termites. Ethol. Ecol. Evol. 3: 15-19.

Fontana F. \& Amorelli M. 1975: Chromosome complement of Kalotermes flavicollis Fabr. (Isoptera: Kalotermitidae). Boll. Zool. 42: 99-100.

FonTANA F. \& Goldoni D. 1985: The structure of an interchange chain of four chromosomes in Reticulitermes lucifugus (Isoptera: Rhinotermitidae). - Genetica 66: 89-91.

Glugoski L., Deon G., Schott S., Vicari M.R., Nogaroto V. \& Moreira-Filho O. 2020: Comparative cytogenetic analyses in Ancistrus species (Siluriformes: Loricariidae). - Neotrop. Ichthyol. 18(2): e200013, 16 pp.

HamiLton W.D. 1964: The genetical evolution of social behaviour. II. - J. Theor. Biol. 7: 17-52.

Husseneder C., Brandl R., Epplen C., Epplen J.T. \& Kaib M. 1999: Within-colony relatedness in a termite species: genetic roads to eusociality? - Behaviour 136: 1045-1063.

InWARD D., BeCCALoni G. \& EgGLeton P. 2007: Death of an order: A comprehensive molecular phylogenetic study confirms that termites are eusocial cockroaches. - Biol. Lett. 3: 331-335.

John B. \& LewIS K.R. 1958: Studies on Periplaneta americana III. Selection for heterozygosity. - Heredity 12: 185-197.

John B. \& LewIS K.R. 1959: Selection for interchange heterozygosity in an inbred culture of Blaberus discoidalis (Serville). - Genetics 44: 1-11.

John B. \& QiJRaishi H.B. 1964: Studies on Periplaneta americana IV. Pakistani populations. - Heredity 19: 147-156.

Krishna K., Grimaldi D.A., Krishna V. \& Engel M.S. 2013 Treatise on the Isoptera of the world: Vol. 1-7. - Bull. Am. Mus. Nat. Hist. 377: 2704 pp.

LACY R.C. 1980: The evolution of eusociality in termites: A haplodiploid analogy? - Am. Nat. 116: 449-451.

LACY R.C. 1984: The evolution of termite sociality: Reply to Leinaas. - Am. Nat. 123: 876-879.

Legendre F., Nel A., Svenson G.J., Robillard T., Pellens R. \& GrandColas P. 2015: Phylogeny of Dictyoptera: Dating the origin of cockroaches, praying mantises and termites with molecular data and controlled fossil evidence. - PLOS ONE 10(7): e0130127, 27 pp.

LeINAAS H.P. 1983: A haplodiploid analogy in the evolution of termite eusociality? Reply to Lacy. - Am. Nat. 121: 302-304.

Levan A., Fredga K. \& SAndBerg A.A. 1964: Nomenclature for centromeric position on chromosomes. - Hereditas 52: 201220.

LewIS K.R. \& John B. 1957: Studies on Periplaneta americana II. Interchange heterozygosity in isolated populations. - Heredity 11: 11-22.

Light S.F. 1938: Parthenogenesis in Termites. - Anat. Rec. 72: Suppl. 102.

Light S.F. 1942: The determination of the castes of social insects. - Quart. Rev. Biol. 4: 312-326.

Lo N., Tokuda G., Watanabe H., Rose H., Slaytor M., Maekawa K., BANDI C. \& NodA H. 2000: Evidence from multiple gene sequences indicates that termites evolved from wood-feeding cockroaches. - Curr. Biol. 10: 801-804.
Lo N., Luykx P., Santoni R., Beninati T., Bandi C., Casiraghi M., Wen-hua L., ZaKharov E.V. \& Nalepa C.A. 2006: Molecular phylogeny of Cryptocercus wood-roaches based on mitochondrial COII and 16S sequences, and chromosome numbers in palearctic representatives. - Zool. Sci. 23: 393-398.

Lo N., Tong K.J., Rose H.A., Ho S.Y.W., Beninati T., Low D.L.T., Matsumoto T. \& Maekawa K. 2016: Multiple evolutionary origins of Australian soil-burrowing cockroaches driven by climate change in the Neogene. - Proc. R. Soc. (B) 283(1825): 20152869, 8 pp.

LUYKX P. 1983: XO:XX Sex chromosomes and Robertsonian variation in the autosomes of the wood-roach Cryptocercus punctulatus (Dictyoptera: Blattaria: Cryptocercidae). - Ann. Entomol. Soc. Am. 76: 518-522.

LUYKX P. 1987: Variation in sex-linked interchange heterozygosity in the termite Incisitermes schwarzi Banks (Insecta: Isoptera) on the island of Jamaica - Genome 29: 319-325.

LUYKX P. 1990: A cytogenetic survey of 25 species of lower termites from Australia. - Genome 33: 80-88.

LuYkX P. \& Syren R. M. 1979: The cytogenetics of Incisitermes schwarzi and other Florida termites. - Sociobiology 4: 191209.

Luykx P., Nickle D.A. \& Crother B.I. 1990: A morphological, allozymic, and karyotypic assessment of the phylogeny of some lower termites (Isoptera: Kalotermitidae). — Proc. Entomol. Soc. Wash. 92: 385-399.

Martins V.G. \& Mesa A. 1995: Two permanent linear chains of sex chromosomes in Neotermes fulvescens and karyotypes of two other neotropical Kalotermitidae species (Insecta, Isoptera). - Genome 38: 958-967.

Matthey R. 1945: Cytologie de la parthénogenèse chez Pycnoscelus surinamensis. - Rev. Suisse Zool. 52: 1-109.

Matthey R. 1948: La formule chromosomiale de la race bisexuée de Pycnoscelus surinamensis L., comparée à celle de la race parthénogénétique. - Experientia 4: 308-309.

Morse M. 1909: The nuclear components of the sex cells of four species of cockroaches. - Arch. Zellforsch. 3: 483-520.

Nalepa C.A., Luykx P., Klass K.-D. \& Deitz L.L. 2002: Distribution of karyotypes of the Cryptocercus punctulatus species complex (Dictyoptera: Cryptocercidae) in the southern Appalachians: Relation to habitat and history. - Ann. Entomol. Soc. Am. 95: 276-287.

Nalepa C.A., Shimada K., MaeKawa K. \& Luykx P. 2017: Distribution of karyotypes of the Cryptocercus punctulatus species complex (Blattodea: Cryptocercidae) in Great Smoky Mountains National Park. - J. Insect Sci. 17(3): 69, 11 pp.

Отто S.P. \& Whitton J. 2000: Polyploid incidence and evolution. - Annu. Rev. Genet. 34: 401-437.

PizA S.D.T. 1958: Cytological studies on Brazilian Blattidae: (with 61 figures). - Caryologia 10: 415-442.

Ross M.H. \& Cochran D.G. 1971: Cytology and genetics of a pronotal-wing trait in the German cockroach. - Can. J. Genet. Cytol. 13: 522-535.

Ross M.H. \& Cochran D.G. 1975: Two new reciprocal translocations in the German cockroach: Cytology and genetics of $\mathrm{T}(3 ; 12)$ and $\mathrm{T}(7 ; 12)$. - J. Hered. 66: 79-88.

Ross M.H. \& Cochran D.G. 1976: Sterility and lethality in crosses involving two translocation heterozygotes of the German cockroach, Blattella germanica (L.). - Experientia 32: 445-447.

Ross M.H. \& Cochran D.G. 1977: Analysis of a double reciprocal chromosome translocation in the German cockroach. - J. Hered. 68: 231-237. 
Ross M.H. \& Cochran D.G. 1979: Properties of a 3-chromosome double translocation heterozygote in the German cockroach. J. Hered. 70: 259-266.

Ross M.H. \& Cochran D.G. 1981: Synthesis and properties of a double translocation heterozygote involving a stable ringof-six interchange in the German cockroach. $-J$. Hered. 72: $39-44$.

Rотн L.M. 1967: Sexual isolation in parthenogenetic Pycnoscelus surinamensis and application of the name Pycnoscelus indicus to its bisexual relative (Dictyoptera: Blattaria: Blaberidae: Pycnoscelinae). - Ann. Entomol. Soc. Am. 60: 774-779.

Rотн L.M. 1973: Brazilian cockroaches found in birds' nests, with descriptions of new genera and species. - Proc. Entomol. Soc. Wash. 75: 1-27.

Roth L.M. \& Cohen S.H. 1968: Chromosomes of the Pycnoscelus indicus and P. surinamensis complex (Blattaria: Blaberidae Pycnoscelinae). - Psyche 75: 53-76.

Rowell D.M. 1986: Complex sex-linked translocation heterozygosity and its role in the evolution of social behaviour. - Can. J. Genet. Cytol. 28: 168-170.

SAKAMOTO Y. \& ZACARO A.A. 2009: LEVAN, an ImageJ Plugin for Morphological Cytogenetic Analysis of Mitotic and Meiotic Chromosomes. URL: http://rsbweb.nih.gov/ij/plugins/ levan/ levan.html.

Stevens N.M. 1905: Studies in Spermatogenesis with Especial Reference to the "Accessory Chromosome". Carnegie Institution of Washington, Washington D.C., 33 pp.

SuOMAlainen E. 1946: Die Chromosomen verhältnisse in der Spermatogenese einiger Blattarien. - Ann. Acad. Sci. Fenn. (A) 10: 1-60

Sylvester T., HJelmen C.E., Hanrahan S.J., Lenhart P.A., JohnSton J.S. \& Blackmon H. 2020: Lineage-specific patterns of chromosome evolution are the rule not the exception in Polyneoptera insects. - Proc. R. Soc. (B) 287(1935): 20201388, 9 pp.

Syren R.M. \& Luykx P. 1977: Permanent segmental interchange complex in the termite Incisitermes schwarzi. - Nature 266: 167-168.

SyREN R.M. \& LUYKX P. 1981: Geographic variation of sex-linked translocation heterozygosity in the termite Kalotermes approximatus Snyder (Insecta: Isoptera). - Chromosoma 82: 65-88.

The Tree of Sex Consortium 2014: Tree of sex: A database of sexual systems. - Sci. Data 1: 140015, 8 pp.

TRUCKENBRODT W. 1964: Zytologische und entwicklungsphysiologische Untersuchungen am Ei von Kalotermes flavicollis Fabr., Reifung, Furchungsablauf und Bildung der Keimanlage. - Zool. Jb. Abt. Anat. Ontog. Tiere 81: 359-434.

VINCKE P.P. 1974: Chromosome numbers in Termitidae (Isoptera). - Curr. Sci. 43: 698-699.

VINCKE P.P. \& TILQUIN J.P. 1978: A Sex-linked ring quadrivalent in Termitidae (Isoptera). - Chromosoma 67: 151-156.

Wang L., Liao S., Liu M., Deng W., He J., Wang Z. \& Che Y. 2019: Chromosome number diversity in Asian Cryptocercus (Blattodea, Cryptocercidae) and implications for karyotype evolution and geographic distribution on the Western Sichuan Plateau. - Syst. Biodiv. 17: 594-608.

WassiliefF A. 1907: Die Spermatogenese von Blatta germanica. - Arch. Mikroscop. Anat. 70: 1-42.

White M.J.D. 1976: Animal Cytogenetics; Vol. 3: Insecta; Blattodea, Mantodea, Isoptera, Grylloblattodea, Phasmatodea, Dermaptera, and Embioptera. Gebr. Borntraeger, Berlin, 75 pp.

Received December 31, 2020; revised and accepted May 26, 2021 Published online July 2, 2021 